\title{
Digital Manufacturing of Indian Traditional Handicrafts
}

\author{
Vishal Gulati \\ Department of Mechanical Engineering \\ GJ University of Science and Technology \\ Hisar (India)
}

\author{
Sonu Mathur \\ Department of Mechanical Engineering \\ GJ University of Science and Technology \\ Hisar (India)
}

\begin{abstract}
In the design world, the driving force of computation tools of modern computer is moving towards to expertise craftwork and customization offers new paradigms for modeling and manufacturing of traditional artifacts. Craft-specific CAD tools present new opportunities for novice user to participate in design process. Computational tools in conjugation with digital manufacturing are turning towards to become an integral element of professional art and design, as these are compatible with traditional crafts. The hybrid integration of design tools, digital manufacturing and traditional techniques of crafts reflect a new way for both traditional handicrafts as well as contemporary issues. This integration of design tools with the traditional crafts has a greater potential for craft work and enhance creativity of craftsman in future.
\end{abstract}

\section{Keywords}

Indian Handicraft, CAD/CAM, Digital Manufacturing

\section{INTRODUCTION}

Indian handicraft sector includes production of delicate handicrafts using diverse raw materials in different parts of the country, majorly jewelry designing and manufacturing, stone work, wood carving, glass etching, clay work, metal and leather work, textile printing and embroidery etc. Various artists want to harness their crafting strength by the use of $\mathrm{CAD}$ and digital fabrication. This may possibly be through computer assisted designing and fabrication of handicraft products. Two hybrid approaches are being employed; one is to create a customized CAD tool that provides ways of designing with traditional manufacturing and other is to merge traditional handcrafting with digital manufacturing. First approach increases design possibilities used in traditional making practices for novice to expert designers and second serves to transfer traditional crafts to the digital domain to a large extent.

There has been growth in digital fabrication methods that allow for easily realizing free-form handicraft products in the physical world. The inclination towards digital fabrication of traditional craft products provokes the use of modern CAD packages for creating craft-specific CAD tool. Development of craft-specific CAD tools would enable the designers to reconfigure virtual and physical parts. But, modern CAD tools which have largely been developed in an industrial context, lack a means of incorporating traditional operations and techniques in creating handicraft products. These CAD tools could be customized for designing traditional craft into CAD paradigms by carrying out software implementation of all the sequential steps needed to shape craft designs. The craftspecific CAD tools would support computer assisted manufacturing to digitally fabricate the products.
Recently, developed CAD/CAM technologies are employed more and more in industry to increase efficiency and speed up product development time meanwhile craftsmen tend to their practices using CAD/CAM technologies.

Somewhere, Craftsperson's are not willing to replace existing skills with new CAD/CAM tools but the lack of visual tools in traditional methods for creative designs is attracting towards CAD. Moreover, handicrafts products are gradually facing competition from machine made products. In this context, the use of CAD/CAM within craft work is not ruled out as violation traditional skills and can be used as supportive tools to craftsman to explore their artwork and access to digital manufacturing. But, the industrial package are far away from the reach of craftsman's, so it is necessary to develop a library of tools that is available in public domain and can be used by an artisan for expanding the design envelope in an application area of handicraft [1]. Therefore, an idea of automation of craftsmanship can be thought which brings convergence of craftwork and technology as a fusion of CAD/CAM (Table 1). Here automation is certainly not the aim; the priority is to provide tools to designers.

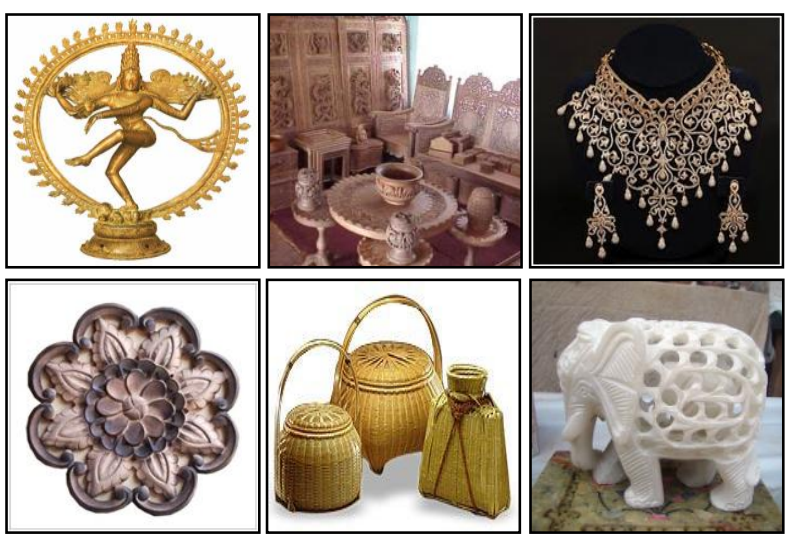

Fig.1: Traditional Handicraft Products
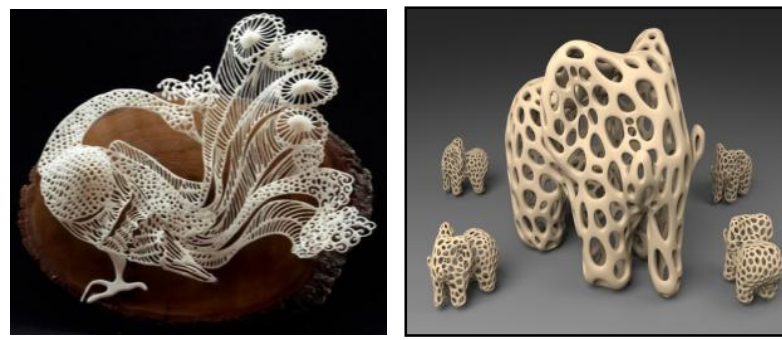

Fig. 2: 3D Printed Tangible Artifacts 
Table 1: Indian Traditional Handicrafts and Fabrication Techniques

\begin{tabular}{|l|l|l|l|c|c|}
\hline $\begin{array}{l}\text { Traditional } \\
\text { Handicrafts }\end{array}$ & Culture/ Craft & Production Methods & \multicolumn{2}{|c|}{ Modern Manufaring Methods } \\
\cline { 3 - 5 } & & & $\begin{array}{l}\text { Layered } \\
\text { Manufacturing }\end{array}$ & \multicolumn{2}{l}{$\begin{array}{l}\text { Laser cutting } \\
\text { Machine }\end{array}$} \\
\hline Furniture & Wood crafts & $\begin{array}{l}\text { Wood Carving, Relief } \\
\text { Carving }\end{array}$ & & $\checkmark$ \\
\hline $\begin{array}{l}\text { Pottery \& Clay } \\
\text { objects }\end{array}$ & Ceramic crafts & Moulding & $\checkmark$ & $\checkmark$ & $\checkmark$ \\
\hline Metal wares & Metal crafts & $\begin{array}{l}\text { Casting and Die } \\
\text { Striking Moulding, }\end{array}$ & $\checkmark$ & $\checkmark$ & $\checkmark$ \\
\hline Jewellery & $\begin{array}{l}\text { Indian Traditional } \\
\text { Jewellery }\end{array}$ & $\begin{array}{l}\text { Clay } \\
\text { Stamping, }\end{array}$ & $\checkmark$ & $\checkmark$ \\
\hline Leather Products & Leather Work & Stamping & & $\checkmark$ \\
\hline $\begin{array}{l}\text { Handprinted Textiles } \\
\text { S Scarves }\end{array}$ & Textile Printing & Stamping & & $\checkmark$ \\
\hline Stone Carving & Stone Work & Engraving, & & $\checkmark$ \\
\hline Latticed Screens & Wood crafts & Fret-working, Etching & & $\checkmark$ \\
\hline Chicken Embroidery & $\begin{array}{l}\text { Embroidery } \\
\text { Work }\end{array}$ & Needle Movement & & $\checkmark$ & $\checkmark$ \\
\hline
\end{tabular}

\section{WIRE JEWELRY}

Wire twisting and wrapping is one of the oldest techniques for making handmade jewelry. Creating this artwork requires a specialized skill for the present-day jeweler, in ancient times this completely handcrafted technique was a customary skill of all jewelers. In this technique the different gauge of wire are twist, bend and wrapped bent into a loop or a decorative shape [3]. Wire components/shapes are then connected to one another using mechanical techniques with no soldering or heating of the wire. These shapes can be defined in parametric forms which yield a wide range of variations in these shapes.

The modeling process includes selection of the motif shape from the library and shape generation followed by definition of parameters through an interface created for wire jewelry for the selected motif [4]. Therefore, this parametric CAD tool is to produce wide range of jewelry designs in this particular class of jewelry.

Steps in jewelry modeling are as follow:

i). The basic geometric shapes are parameterized according to shape geometry.

ii). The shape coordinate points are defined in form (x; $\mathrm{y})=[\mathrm{x}(\mathrm{t}) ; \mathrm{y}(\mathrm{t})]$, parameter $\mathrm{t}$ increases, and a shape is traced.

iii). A cross-section profile is generated on a plane normal to geometric shape.

iv). A twist or sweep is produced followed by parameter of shape and twist, creating a decorative shape of wire jewelry.

v). The modeling parameters other than that defines curve are number of wires in the wire strand $(N)$, radius of wires $\left(R_{w}\right)$ and number of turns in the wire strand $(n)[5]$.

\section{CARVED JEWELRY}

Carved jewelry is a form of jewelry having small internal cavities as generated with thin sharp tool on the surface of sheet metal. This CAD paradigm produces traditional class of Indian carved jewelry $[6,7]$. Digitalization has been included in jewelry production through $\mathrm{CAD}$ and layered manufacturing. The paradigm is implemented under the Active $\mathrm{X}$ and Visual Basic Application (VBA) programming environment using AutoCAD.
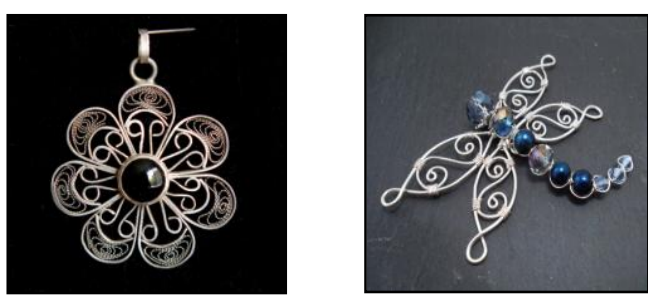

(a)
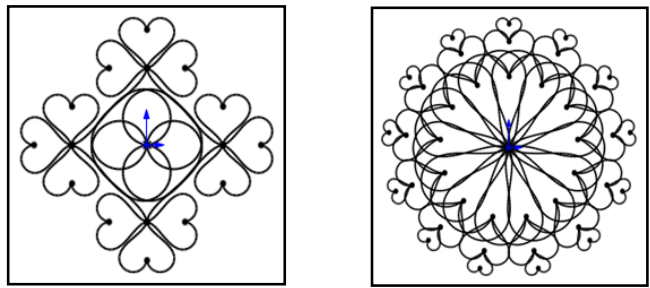

(b)
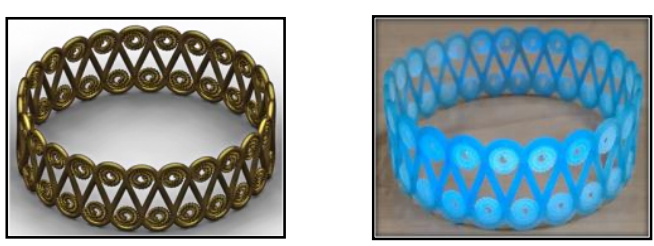

(c)

Fig. 3: (a) Traditional Wire Jewelry (b) Patterns generated from decorative shapes (c) A rendered image and 3D printed model

The jewelry design steps which are programmed to be executed automatically in CAD environment are as follows:

i). A voxel element parameterized as voxel signature having a set of modeling parameters and represented as $\mathrm{V}-\mathrm{P} / \mathrm{L} / \mathrm{H} / \mathrm{\theta} / \mathrm{X} / \mathrm{Y} / \mathrm{R}$, where $\mathrm{V}$ stands for voxel, $\mathrm{P}$ for maximum number of valid points, $\mathrm{L}$ for size, $\mathrm{H}$ for height and $\theta$ for inclination of side 
surface of voxel element, $\mathrm{X}$ and $\mathrm{Y}$ for variants and $\mathrm{R}$ for radius of center hole.

ii). A CAD block of rectangular array of the voxel in rows and columns ( $\mathrm{R}$ and $\mathrm{C}$ ) is generated according to proportion to the size of jewelry type.

iii). Creating a polar array of the block in the plane about the perpendicular axis passing through any one of the valid points $(\mathrm{Pt})$ for an angle $(\theta)$ and a number $(\mathrm{N})$.

iv). Rendering of jewelry model (Fig. 5a).

v). Digital fabrication using layered manufacturing for the production real artifacts (Fig. 5b).
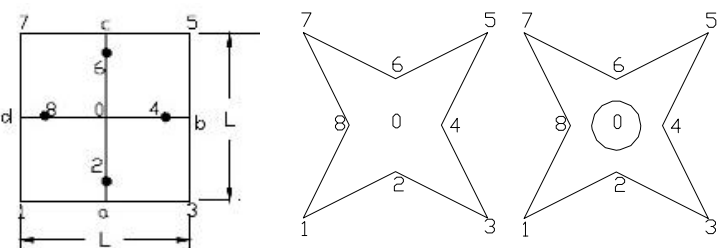

(a)

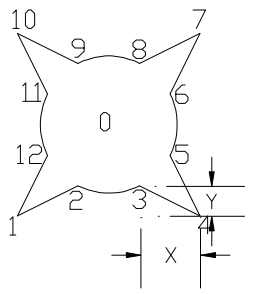

(b)
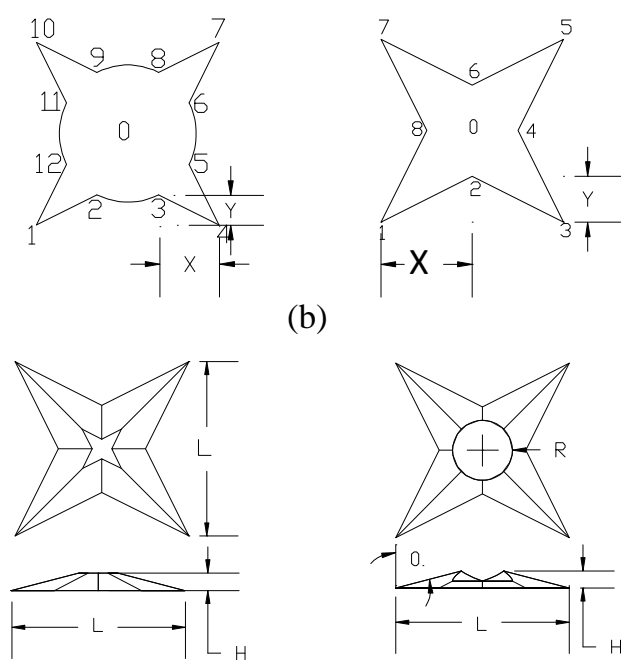

without center hole

(c)

with center hole

Fig. 4: (a) Inscribed square profile and 2D profiles with valid points, (b) voxel element showing variants, (c) extruded voxel element.

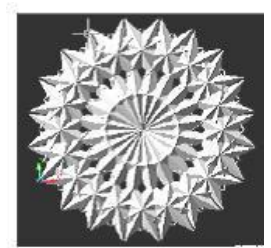

(a)

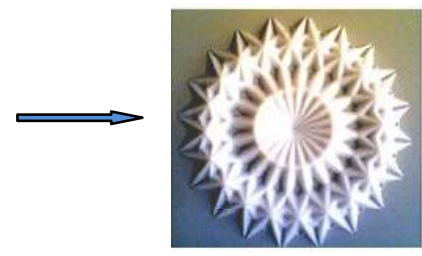

(b)
Fig. 5: (a) Rendered Model (b) Digitally fabricated from

\section{CAD model}

\section{SAHARNPUR WOODCRAFTS}

Saharanpur in Uttar Pradesh is famous worldwide for its woodcrafts, particularly for its unique style of floral motifs carved in low relief on the Sheesham wood (Fig. 6a). The technique of wood carving is a tool assisted method of reducing the wood by skilled hands. This CAD paradigm generates carved sculptured surfaces of woodcrafts using CNC milling machine.

Saharanpur floral motifs are based on the circular geometry and traditionally created using compass drafting. During CAD modeling, floral motif is hierarchically decomposed into identical petals [8]. This representation scheme uses CAD as a design tool that helps the designers/artists to manipulate a set of fundamental motifs and to arrange them into some definite order for generating a pattern. The Modeling steps to be executed programmatically are as follows $[9,10]$ :

i). Modeling of petal in a planar map having a set of points whose coordinates have been devised in terms of the intuitive modeling parameters: $\mathrm{R}$ (Size of the motif), $r$ (Size of central part of the motif) and $n$ (number of petals).

ii). Petal motif as polar array of floral motif (Fig. 6b).

iii). Motif is wrapped on the sculptured surface.

iv). Digital fabrication through $\mathrm{CNC}$ machine (Fig. 6c).
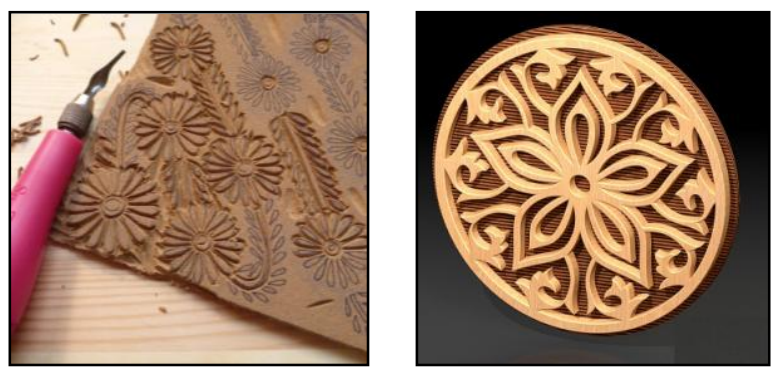

(a)
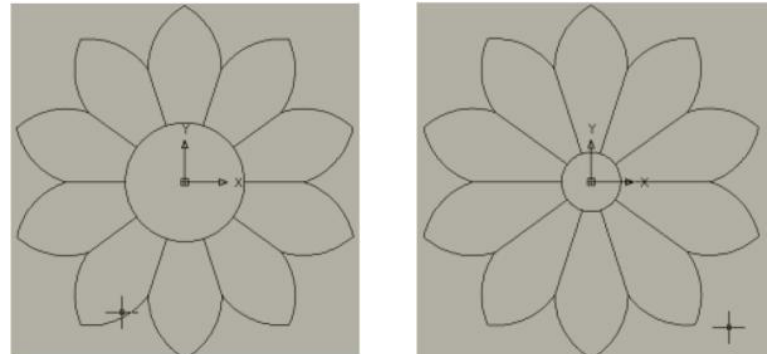

(b)
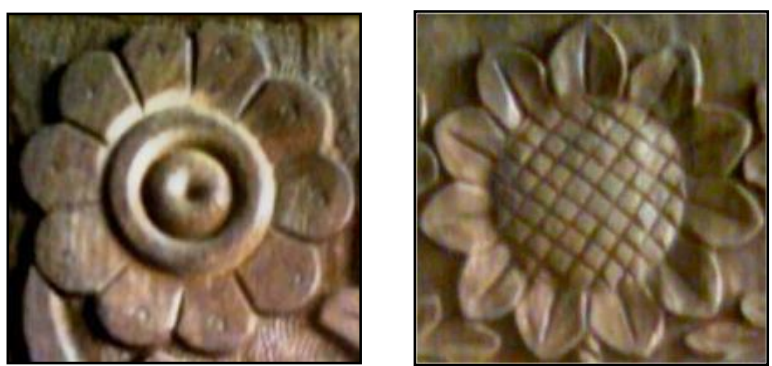

(c)

Fig. 6: Saharanpur Woodcrafts

\section{PIERCED SCREENS}

Traditional latticed screens with Islamic star patterns are used as a decorative element for ornamental products and interior decoration. A star is regarded as a collection of line segments that are joined with each other at their end points. The star patterns for traditional latticed screens are realized as periodic and repeated arrangement of a type of motif/compound-motifs 
[11]. Further, a compound-motif is viewed as an array of different star/rosette motifs. The generated patterns are $2 \mathrm{D}$ in nature and mapped on the planar surface of a material to produce $2 \frac{1}{2} \mathrm{D}$ screens. Modeling steps are as follow:

1. Motif shape defining parameters are: $r$ (size of motif), $\mathrm{n}$ (number of rays), $\theta$ (shape of star), $t$ (line thickness) and $\mathrm{w}$ (width of rosette).

2. Compound-motifs are designed in theme of star shape motif having a central motif in contact with surrounded motifs (Fig. 7a).

3. Arrangement of motif/compound-motif in a pattern is defined by row and column offset.

4. Digital fabrication using laser/water jet cutting by removing material from a planer surface (Fig. 7b).

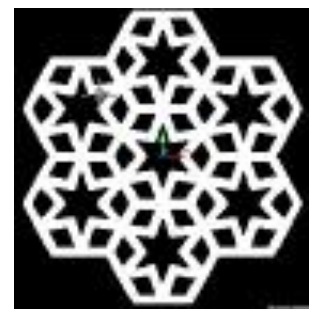

$\mathrm{n}_{1}=6, \mathrm{r}_{1}=1, \theta_{1}=20^{\circ}$ $\mathrm{n}_{2}=6, \theta_{2}=20^{\circ}, \mathrm{n}_{3}=6$, $\theta_{3}=20^{\circ}, \mathrm{t}=0.2$

(a)
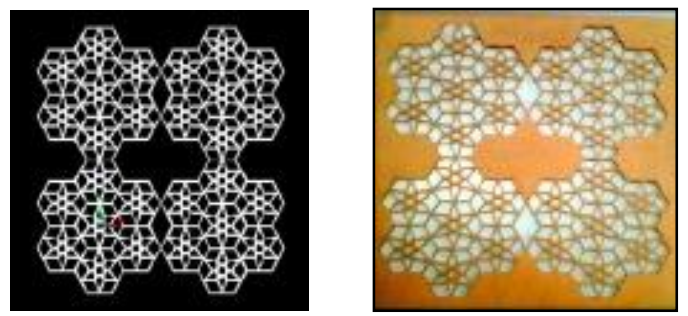

(b)

Fig. 7: Pierced Screens

\section{CONCLUSION}

Traditional crafts are highly unique and have vast potential which needs to be capitalized to create intersection between technology and tradition. Today, CAD/CAM software has ability to design and manufacture the complex geometries that previously were not possible with traditional manufacturing. Digital manufacturing with the appropriate craft-specific tools helps people preserve their tradition and support existing traditional techniques and create new designs. Digital tools are useful in extending traditional work and enhancing traditional skills, without replacing tradition. Present digital technology also allow user to variability in production of goods through an automated process.

\section{REFERENCES}

[1]. Chatterjee, A., Tiwari, A., Mohan Misra, P. and Dhande, S.G., "Designing Handicraft using Information communication technology", Indian Journal of Exports, 12(1), 2008, pp.102-107.

[2]. Turbovich Z.N., Avital I., Mazor G., Das A.K., Kalita P.C., "Personal 3D Printer: Self-design and Manufacturing". In: Chakrabarti A., Chakrabarti D. (eds) Research into Design for Communities, Volume 1. ICoRD 2017.

[3]. Iarussi E., Li W. and Bousseau A., "Wrapit: Computerassisted crafting of wire wrapped jewelry". ACM Transactions on Graphics (TOG). Nov 4; 34(6); 2015, 221.

[4]. Gulati V., Mathur S., "Production of Traditional Twisted Wire Jewelry Designs using Mathematical Shapes", Journal of Material Science and Mechanical Engineering, Vol. 3, Issue7; 2016, pp. 479-484.

[5]. Kaur G., Mathur S., Gulati V., "Shape Grammar Interpreter for Twisted Wire Jewelry". International Journal of Computer Applications 130(8):17-20, November 2015.

[6]. Gulati V., Singh H. and Tandon P.: 2008, "A Parametric Voxel Based Unified Modeler for Creating Carved Jewelry", Computer-Aided Design \& Applications, Vol. 5, Nos. 1-4. Vol. 5, No. 6, pp. 811-821.

[7]. Gulati V., Tandon P., Singh H., 2010, "A Jewelry Modeler for the Carved Bangles", International Journal of Computer Applications, Vol. 5, No. 2, pp. 25-27.

[8]. Gulati V. and Katyal P. "A Hierarchic Representation Scheme For Generating Decorative Patterns", International Journal of Current Research Vol. 3, Issue, 11, pp.186-189, October, 2011.

[9]. Gulati V., Singh K., Katyal P., "A CAD Paradigm for Generating Woodworking Motifs", International Journal of Computer Applications, Vol. 47, No. 5, 2012, pp. 3840.

[10].Gulati Vishal and Kulwant Singh and Tandon Puneet, 2012, "Computer Generated Indian Traditional Decorative Patterns for Woodcraft, International Conference on Innovations in Design and Manufacturing, PDPM-IIITDM Jabalpur, December 5-7, 2012.

[11].Gulati, V., and Katyal P., "Parameterized Modeling of Star Patterns for Traditional Latticed Screens." International Journal of Computer Applications, Volume 11(1), December 2010, pp 28-36.

[12].Mellis, D., Follmer, S., Hartmann, B., Buechley, L., \& Gross, M. D., "FAB at CHI: digital fabrication tools, design, and community". In CHI'13 Extended Abstracts on Human Factors in Computing Systems, April 2013, (pp. 3307-3310). ACM.

[13].Walters, P. and Davies, K., "3D printing for artists: research and creative practice", Rapport: Journal of the Norwegian Print Association, 1; 2010, pp. 12-15. 